\title{
Tecnologías de
}

\section{Información y}

Comunicación y

la Enseñanza del

Español on line: un

análisis de discursos

de las disciplinas

virtuales del curso

de Letras Español

a distancia de la

UAB-UESPI

Luciana Maria Libório Eulálio

Recebido em: 20 de outubro de 2016

Aceito em: 20 de dezembro de 2016

Mestre em Linguística na área de Estudos de Linguagem pela Universidade Federal do Piaú. Especialista em Língua Espanhola pela Universidade Estadual do Piaú, em Docência no Ensino Superior pela Pontíícia Universidade Católica de Minas Gerais-PUC - MG e em Educação Continuada e a Distância pela UAB-UnB. É Professora Assistente $\mid$ do quadro éretivo do curso de Licenciatura Plena em Letras Espanhol da Universidade Estadual do Piauí (UESPI). Possui experiência na área de Educação a Distância (EaD) onde desenvolveu atividades como tutora, professora pesquisadora e formadora atuando na plataforma Moodle.

Contato: lueulalio@hotmail.com 
KEYWORDS: Spanish; discourse; This article presents a comparative analysis of the discourses produced online education. in the disciplines Culture of Spanish-speaking people, Supervised Practice IV, Spanish Literature I and Spanish Language IV, which are part of the Language Arts (Spanish) online course offered by UAB-UESPI. It focuses on the production of meanings about the methodology of Spanish teaching at the level of an undergraduate online course. To do so, it analyzes the presence of enunciation strategies in the way these disciplines show, interact and seduce students. The study adopts the Discourse Analysis as its methodological and theoretical orientation and is developed following a qualitative and interpretative approach. In order to discuss the concepts of distance education, network society, technology, digital literacy and virtual environment, we rely upon the reflections proposed by Kenski (2007), Preti (2005), Castells (1999), Dalmonte (2009) Lévy (1993), Snyder (2009). Besides, we discuss the studies developed by Bakthin (2003), Foucault (2009), Joly (2005) and Pinto (2002) to better understand the concepts of language, subject, enunciative heterogeneities and speeches. Finally, we consider the Theory of Social Discourses proposed by Pinto (2002), and the concept of Reading Contract developed by Verón (2004).

Palabras Clave: español; Este artículo presenta un análisis comparativo de los discursos discurso; educación on line. producidos por las disciplinas virtuales Cultura de los Pueblos de lengua Española, Pasantía supervisada N, Literatura Española I y Lengua Española $N$ del curso de Letras Español a distancia de la UAB-UESPI. Su objetivo central es investigar cómo se construyeron los sentidos sobre la metodología de enseñanza del español a nivel de un curso de graduación vía internet, analizando cuáles son las estrategias 


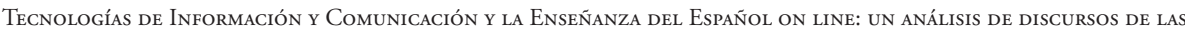
disciplinas virtuales del curso de Letras Español a distancia de la UAB-UESPI

Luciana Maria Libório Eulálio

de enunciación presentes en los modos de mostrar, interactuar y seducir de esas disciplinas. La investigación adopta como perspectiva teóricometodológica el Análisis del Discurso y es de carácter cualitativo e interpretativista. Como referencial teórico sobre Educación a Distancia, sociedad en red, tecnologías, literacidad digital y ambiente virtual, nos apoyamos en Kenski (2007), Preti (2005), Castells (1999), Dalmonte (2009), Lévy (1993), Snyder (2009). Sobre lenguaje, sujeto, heterogeneidades enunciativas y discursos, en Bakthin (2003), Foucault (2009), Joly (2005) y Pinto (2002). El estudio también se apoya en la la Teoría de los Discursos Sociales (Pinto, 2002) y en el concepto de Contrato de Lectura (Verón, 2004). 


\section{INTRODUCCIÓN}

Los cambios paradigmáticos han revelado varias tendencias del mundo actual y una de ellas es la educación, que busca la formación integral de los individuos, futuros profesionales de las más diferentes áreas. El sector educacional brasileño sintió esa necesidad de modo más intenso a partir de la nueva Ley de Directrices de Base de la Educación - LDB (Demo, 1997), y de los Parámetros Curriculares Nacionales - PCN establecidos por el Ministerio de la Educación. Primero, el decreto del MEC 2.253 del 18 de octubre de 2001 pasó a garantizar que las universidades pudieran ofrecer por lo menos un $20 \%$ de sus disciplinas regulares en la modalidad online, lo que ya nos enseña la génesis de la educación a distancia on line en Brasil. A continuación vino el decreto 4.059 \2004 y el Decreto 5.622\2005, dando a las Instituciones de Enseñanza Superior (IES) la oportunidad de trabajar sus contenidos vía radio, televisión, computadora e internet (on line).

El objetivo de este artículo es investigar cómo se construyen en la actualidad los discursos sobre las nuevas formas de enseñar por internet, considerando que las plataformas de lenguaje computacional abrigan esos varios discursos y también funcionan como elementos de mediación de la relación disciplina versus profesor versus alumno. Para ello analizaremos las disciplinas virtuales Cultura de los Pueblos de lengua Española, Pasantía supervisada IV, Literatura Española I y Lengua Española IV del curso de Letras Español a Distancia de la UAB-UESPI.

Según Castells (1999), en las economías capitalistas se adoptaron medidas que llevan a un nuevo orden y forma de mantener el capital a través de sus procesos de globalización presentes en sus diversos sectores 


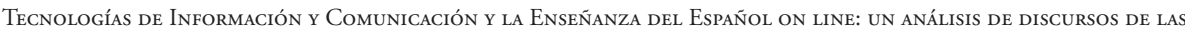
disciplinas virtuales del curso de Letras Español a distancia de la UAB-UESPI

llevando a una flexibilización organizacional y a un mayor poder para gestionar sus relaciones con el trabajo. Estamos hablando de un Capitalismo Informacional que tiene como base la cultura y que es propulsada por esta tecnología. En Ruiz $(2002,5)$ se lee:

Bajo el paradigma informacional emerge una nueva cultura donde las expresiones y la creatividad humana son reguladas e hiperligadas en un hipertexto electrónico global que modifica sustancialmente las formas sociales de espacio y tiempo. (Ruiz, 2002, 5) (Traducción propia.) ${ }^{1}$

En esa misma línea de pensamiento, con la llegada de la revolución de las tecnologías de información y comunicación simbolizada por la internet, Lévy (1993) nos dice que la educación on line pasa a ser un fenómeno de la cibercultura, entendida como una reunión de prácticas sociales, modos de pensamiento, actitudes, modos de acceso a la información y, sobretodo, de valores ligados a ese nuevo ambiente de comunicación, que surge interconectado con computadoras de todo el mundo y también con sus memorias. Este ambiente es el denominado ciberespacio. La cultura escrita conquista dicho espacio virtual, con el cual se reconfiguran y recrean nuevos géneros discursivos que forman parte de un nuevo tipo de literacidad digital.

Con apoyo en las teorías del Análisis de Discursos (AD), esperamos, al fin del análisis, verificar en ese tipo de literacidad cómo se están construyendo

1 Sob o paradigma informacional emerge uma nova cultura onde as expressóes e a criatividade humana são padronizadas e (hiper)ligadas em um hipertexto eletrônico global que modifica substancialmente as formas sociais de espaço e tempo (...) (Ruiz, 2002, 5) 
los discursos de las disciplinas virtuales del curso de Letras Español a Distancia del Estado de Piauí.

Partimos de la hipótesis de que las representaciones didáctico-pedagógicas identificadas en las disciplinas estudiadas, proponen diferentes construcciones de sentido por la relación de conflictos entre sus enunciadores en el interior de la formación discursiva de la Institución Social Educación a Distancia.

\section{EDUCACIÓN A DISTANCIA ON LINE EN EL ORDEN DE SUS DISCURSOS Y}

\section{LAS DISCIPLINAS VIRTUALES EN LENGUA ESPAÑOLA.}

La Teoría de los Discursos Sociales adoptada por Pinto (2002) y Verón (2004) trabaja con los procesos de constitución de los discursos y estos pueden ser definidos, en la perspectiva de la $\mathrm{AD}$, como los lugares del trabajo social de la producción de sentidos, los cuales deben ser interpretados no como un espejo de la realidad, sino como una construcción y representación de esta realidad, tomando en cuenta la perspectiva de alteridad. De ese modo, los sentidos producidos por los discursos sociales no representan algo concreto, sino que son percibidos entre los sujetos, por los efectos de los cambios de los lenguajes condicionados por las formaciones discursivas de las instituciones sociales en las cuales los actores -sujetos sociales- participan. Por eso, la disponibilidad de las disciplinas investigadas en la modalidad virtual fue condicionada por los discursos de la digitalización de las informaciones, y por consiguiente, de la educación on line.

La educación a distancia on line, tratada como una Institución Social con formación discursiva propia, se ha revelado a lo largo de su existencia como un modelo de recontextualización de enseñanza y ha producido discursos 


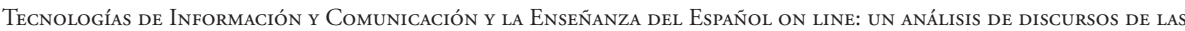
disciplinas virtuales del curso de Letras Español a distancia de la UAB-UESPI

dirigidos a la inclusión digital y a la democratización de la educación, una exigencia del nuevo paradigma de la cual emerge. En Preti (2005), se lee:

la educación, en el contexto del nuevo paradigma ya no puede ser pensada como un sistema cerrado. Como práctica social, debe pensarse en su relación con otras prácticas, en un determinado contexto social, económico, político y cultural, vale decir, como un sistema abierto. Como institución social, se cruza en varios aspectos con la sociedad como un todo, estando sujeta a los mismos movimientos económicos, culturales y políticos de esta. (Preti, 2005, 56).² (Traducción propia)

Se observa, según Kenski (2007), que estamos viviendo un nuevo contexto de relaciones sociales y una nueva era en la educación resultante de varios cambios ocurridos a lo largo de esos últimos años, especialmente en lo que concierne al campo tecnológico, en el cual su gran avance facultó la aparición de las llamadas Nuevas tecnologías de Comunicación e Información (NTIC) que nos imponen, en definitivo, un nuevo paradigma tecnológico simbolizado por la internet y caracterizado como relevante en términos de su alcance social, económico, cultural y educativo, aunque sepamos que gran parte de la sociedad brasileña aún vive una situación de infoexclusión. Sobre las NTIC podemos decir que revela cierta ambigüedad materializada no sólo en su carácter utilitario, sino en su propia constitución. En Pucci

2 A educação, no contexto do novo paradigma, não pode mais ser pensada como um sistema fechado. Como prática social, precisa ser pensada em relação a outras práticas, em um determinado contexto sócio-econômico, político e cultural; portanto, como um sistema aberto. Como instituiçáo social, intersecta-se sob vários aspectos, com a sociedade como um todo, estando sujeita aos mesmos movimentos econômicos, culturais e políticos dela. (Preti, 2005, 56). 
(2006), se lee esta cita de Adorno (1995) de su ensayo "Educação após Auschwitz":

Un mundo como el actual, en que la tecnología ocupa posición-clave, produce personas tecnológicas, afinadas con la tecnología [...]. Las personas tienden a considerar la tecnología como algo en sí, como fin en sí mismo, como una fuerza con vida propia [...] Los medios - y la tecnología es la esencia de los medios para la autorrepresentación de la especie humana - son fetichizados, porque las finalidades - una existencia digna del ser humano - son encubiertas y arrancadas del consciente humano (Pucci, 2006, 52). ${ }^{3}$ (Traducción propia).

Las palabras del autor sugieren que la ambigüedad presente en el valor de las tecnologías se manifiesta tanto por su utilidad como por el hecho de forman parte constitutiva e inherente de las sociedades industriales, $y$ en consecuencia, tomadas como algo en sí mismas y no como un medio para que el hombre alcance su finalidad en cuanto ser en el mundo: su existencia en este mundo. Las tecnologías son asumidas no solo como un modus operandi, sino como un modus vivendi.

El surgimiento de la sociedad de red, según Castells (1999), marcó el fin de una era y el comienzo de otra: la era de la información, que se basa en una revolución tecnológica con capacidad de penetración en todos los ámbitos

3 Um mundo como o atual, em que a tecnologia ocupa posição-chave, produz pessoas tecnológicas, afinadas com a tecnologia [...]. As pessoas tendem a considerar a tecnologia como algo em si, como fim em si mesmo, como uma força com vida própria [...] Os Meios - e a tecnologia é a essência dos meios para a autorrepresentação da espécie humana - são fetichizados, porque as finalidades - uma existência digna do ser humano - são encobertas e arrancadas do consciente humano (Pucci, 2006, $52)$. 


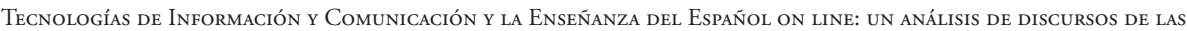
disciplinas Virtuales del curso de Letras Español a distancia de la UAB-UESPI

de la actividad humana. Con la globalización, -entendida como un proceso resultante de la capacidad de ciertas actividades para funcionar como unidad en tiempo real a una escala planetaria- nos encontramos ante un perfil de alumno que pretende ser autónomo frente a su proceso de aprendizaje y que está expuesto a esos avances tecnológicos en su vida doméstica, cotidiana y fuera de las instituciones escolares.

Dentro de este contexto, la educación a distancia online no se restringe sólo a una nueva modalidad de organización del proceso de enseńanza y aprendizaje, sino que traspasa dicha visión y va más allá de su adjetivación (a distancia), por la propia substancia educativa de que está hecha. Pensar en esta actividad a distancia online requiere pensar la educación como práctica social (Snyder, 2009).

Se advierte así que el orden de los discursos de la educación a distancia on line, inserta en el contexto del nuevo paradigma del siglo XXI, está firmemente relacionada a las fuerzas sociales que la moldearon y a sus condiciones de producción. Parafraseando a Foucault (2009), esos discursos podrán ser borrados pero "conforme una duración que no nos pertenece" (Foucault, 2009, 8) [Traducción propia].

Si antes se valoraba la transmisión unidireccional de la información, en el nuevo orden de discursos de la educación a distancia on line se valora cada vez más la interacción entre los interlocutores. En vez de privilegiar la reproducción de contenidos e informaciones ya existentes de modo pasivo, en este orden de discursos sociales vigora el estímulo dado a la creatividad del alumno y a la educación centrada en él mismo. Decir no a la educación "bancaria" tan bien denunciada por Paulo Freire (1996) y decir sí a la 
pedagogía de la autonomía y de la construcción del conocimiento de forma colaborativa es lo que nos ha instigado a investigar cuáles son los sentidos construidos por la práctica social de enseñanza del español a través del diseño de las disciplinas virtuales analizadas dispuestas en la Plataforma Moodle ${ }^{4}$.

\section{METOdOLOGÍA DE LA INVESTIGACIÓN}

Esa investigación adopta como perspectiva teórico-metodológica la del Análisis de Discursos y es de tipo cualitativa e interpretativista, a través de la cual buscamos verificar las estrategias de enunciación presentes en el modo de decir de las disciplinas, e identificar en sus enunciadores la construcción de sus imágenes (yo discursivo), de la imagen del aluno virtual (tú discursivo), y su relación en y por los discursos. El corpus fue constituido por cuatro disciplinas virtuales del curso de Letras Español a Distancia de la UAB-UESPI: Cultura de los Pueblos de lengua Española, Pasantía supervisada IV, Literatura Española I e Lengua Española IV disponibles en la Plataforma Moodle en los períodos de 2014 a 2015.

El análisis de esas disciplinas se dará desde los tres niveles contextualización vistos en Pinto (2002): el contexto situacional inmediato (la superficie textual de la disciplina dispuesta en la plataforma); el contexto institucional (disciplina virtual de un curso superior on line de Letras Español) y el contexto histórico-cultural (la era de la digitalización de la información

4 Plataforma creada en 2001 por el científico y educador Martin Dougiarmas como sistema de administración de actividades educacionales en ambientes virtuales con comunidades on line. Se trata de un sistema en la lengua inglesa denominado Open Source, que significa abierto, libre y gratuito. 


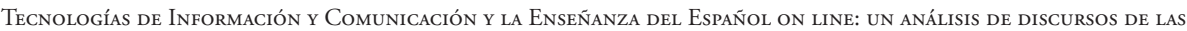
disciplinas Virtuales del curso de Letras Español a distancia de la UAB-UESPI

y del conocimiento y la educación a distancia on line), que está relacionado con las condiciones de producción de las disciplinas investigadas y que, a su vez, incluyen la producción, la circulación vía internet y el consumo de sentidos diseminados en sus superficies textuales.

Pese al orden de discursos de ese contexto histórico cultural en vigor, en la práctica las respuestas dadas a estos retos todavía se revelan incipientes. $\mathrm{Al}$ remitirnos al pensamiento de Michel Foucault (2005), vemos que la estructura de poder y disciplina en la educación tradicional son acontecimientos que poseen raíces históricas profundas. El hecho de introducir en la enseñanza determinada tecnología no garantiza que estaremos libres de los resquicios de la pedagogía tradicional ni que solucionaremos los desafíos impuestos a estas nuevas formas de enseñar. Por ello, no basta introducir nuevas tecnologías en el curso de Letras Español presencial o a distancia; cabe reflexionar con urgencia sobre cómo docentes y discentes las incorporan y cómo su uso puede romper con las barreras conservadoras de la enseñanza tradicional, desafiando las estructuras existentes en vez de reforzarlas.

Optamos por recurrir al Análisis de Discursos alineada a la Teoría de los Discursos Sociales (Pinto, 2002), que afirma que a través de los discursos ocurren las batallas en una sociedad de bienes simbólicos, donde las relaciones no son sólo de causa y efecto, sino de producción de sentidos por las intersubjetividades y que entre las sociedades, instituciones y sujetos disputan un espacio en la red de relaciones sociales.

Desde este punto de vista, hemos adoptado la idea de que los discursos al interior de la Institución Social Educación a Distancia (EaD) son moldeados por sus formaciones discursivas entendidas como "un sistema de reglas 
que funda la unidad de un conjunto de enunciados socio-históricamente circunscritos, determinando lo que puede y debe decirse a partir de una dada posición ideológica en una determinada coyuntura”. (Pinto, 2002, 60). [Traducción propia]

Considerando ese aspecto, las disciplinas analizadas e incluso sus homepages poseen también normas y convenciones y se configuran como un género discursivo que tiene una finalidad social determinada, que es ofrecer al alumno clases de lengua y literatura espańolas con características interactivas.

Como dice Verón (2004), cuando nos posicionamos en los textos, lo que interesa es el cómo decimos y no el qué decimos. Por lo anterior, para este análisis nos interesará no el contenido en sí mismo dispuesto en las disciplinas, sino cómo estas se muestran para seducir al lector y cómo los procesos de producción de sentidos posibilitan la construcción de diferentes discursos sobre esa forma de enseñar en la modalidad on line. Es por ello que en Verón (2004) leemos que las modalidades de decir de los discursos construyen el dispositivo de enunciación que incluyen:

1 La imagen del que habla: llamamos a esta imagen el enunciador. Aquí, el término imagen es metafórico. Se trata del lugar (o los lugares) que se atribuye a sí mismo quien habla. Esta imagen contiene pues la relación del que habla con lo que dice;

2 La imagen de aquel a quien se dirige el discurso: el destinatario. El productor del discurso no solamente construye su lugar o sus lugares en lo que dice; al hacerlo también define a su destinatario; 


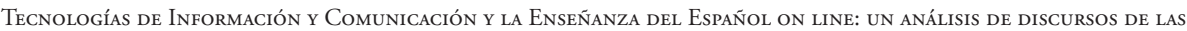
disciplinas Virtuales del curso de Letras Español a distancia de la UAB-UESPI

3 La relación entre el enunciador y el destinatario que se propone en el discurso y a través del discurso (Verón, 2004, 173).

Eso quiere decir que dichos dispositivos de enunciación de un soporte de lectura están articulados a varios aspectos enunciativos como la imagen de quien habla (la imagen de sí: cómo los enunciadores de las disciplinas del curso superior de Letras Espańol a Distancia (UESPI) se construyen en su relación con el otro, en este caso, el alumno); la imagen del lector (la imagen del tú: la imagen del alumno virtual relacionada a las pistas dejadas por los enunciadores para que ese alumno se identifique en el texto y de ahí quiera leerlo) y la imagen de la relación en y por el discurso. Es lo que Verón (2004) denomina Contrato de Lectura, a través del cual realizamos nuestro análisis.

Veremos, pues, que las estrategias de enunciación de las disciplinas analizadas ponen en funcionamiento el lenguaje con la finalidad de desarrollar estrategias de enseñanza sobre lo que se propuso discutir en cada una de ellas.

\section{ANÁlISIS DE LOS DISCURSOS PRODUCIDOS POR LAS DISCIPLINAS VIRTUALES DEL CURSO DE LETRAS ESPAÑOL a Distancia de La LIESPI SEgún la Teoría de los DisCursos SOCIALES.}

Para analizar la imagen discursiva de estas disciplinas, conviene destacar con Pinto (2002) que es en la superficie de los textos donde encontramos las marcas discursivas generadas por los procesos colectivos de producción de sentidos. Dichas marcas o huellas dejadas en los textos generalmente son frutos de cierta regularidad de su existencia y construidas a partir de lo que 
se hace convencional en cada formación discursiva, y cabe interpretarlas y evidenciarlas en el análisis.

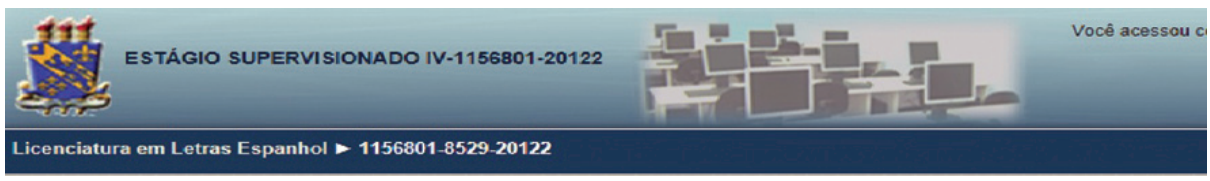

Figura 1 - Banner del curso de Licenciatura Plena en Letras Español de la UESPI

Como vemos en la figura 1, todas las disciplinas de la UAB-UESPI utilizan ese banner como estrategia enunciativa que marca la presencia de la institución o lugar de donde proviene el habla, o sea, es el propio enunciador institucional quien se materializa a través de su blasón y del nombre del curso. Otra estrategia de enunciación marcada es la imagen de varios computadores dispuestos en un aula. Con el uso de ese dibujo se construye una imagen de sí de la institución positiva que adhirió a la enseñanza on line, creando para la universidad la imagen de que esta se inserta en el Orden de los discursos de la Educación a Distancia y de la Sociedad de la Información y del Conocimiento, discursos que están dentro de otro mayor y hegemónico, que es el de la era "globalización" y de la "digitalización" de la información y del conocimiento, y por ello, de la enseñanza y del aprendizaje. En ese banner, se enuncia institucionalmente el curso, Letras Español, su género, Licenciatura, y el nombre de las disciplinas, que en este caso corresponden a Pasantía Supervisada IV. Esta estrategia enunciativa que marca la posición de la UESPI en la educación a distancia on line es parte integrante de los discursos de las disciplinas virtuales y aparecen con cierta regularidad dentro de las plataformas de enseñanza. 


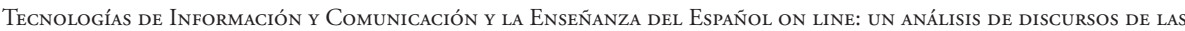
disciplinas VirTuales del curso de Letras Español a distanCia de La UAB-UESPI

Luciana Maria Libório Eulálio

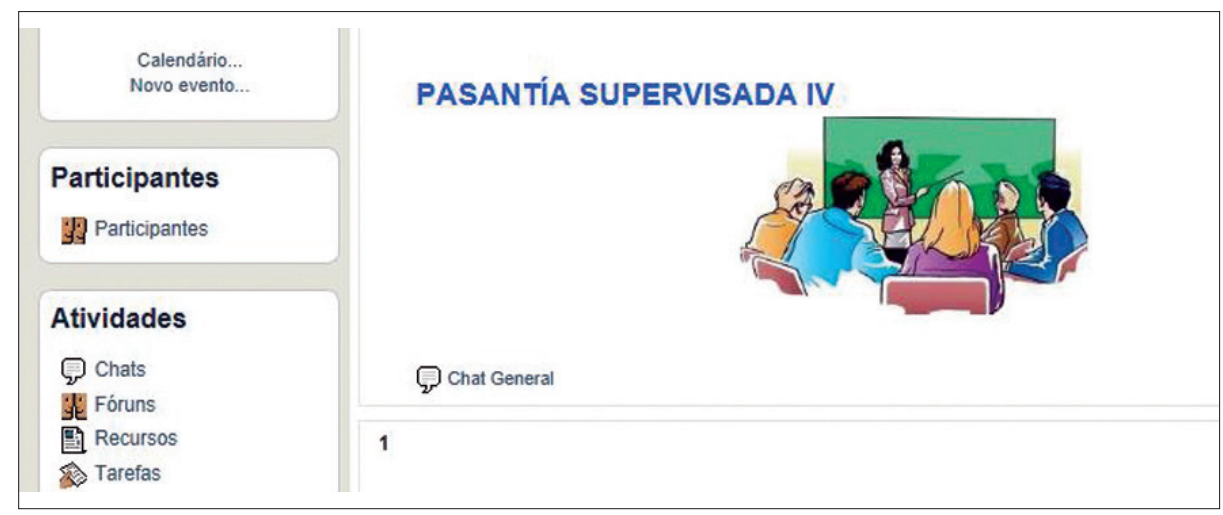

Figura 2 - Pásina de la disciplina Pasantía Supervisada IV

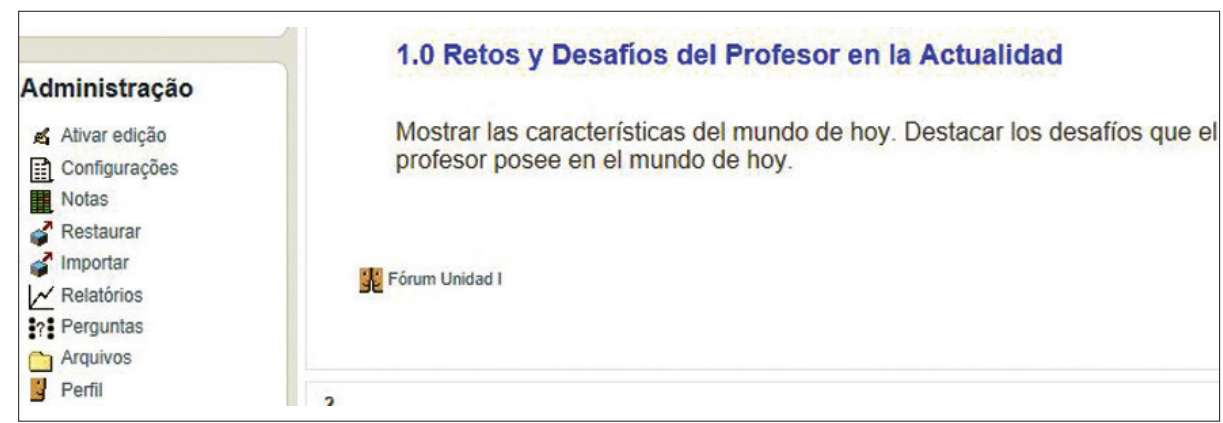

Figura 3 - Página de la disciplina Pasantía Supervisada IV

Este enunciador institucional se marca también al lado izquierdo de la página (fig. 2) en la interface ATIVIDADES con el enlace "tarefa" y en la interface ADMINISTRAÇÂO (fig.3), con los enlaces "notas" y "relatórios". $\mathrm{Al}$ pinchar en estos enlaces, el alumno tiene acceso a un cronograma de actividades y un cuadro de notas que le permite acompañar su desempeño. 
De no hacerlas en el tiempo fijado, no será aprobado. Se puede decir que estamos en un campo de tensiones o de fuerzas sociales en el que es evidente el embate entre discursos de diferentes órdenes, pues mientras se habla a partir de un Orden de discursos conforme los principios de autonomía, colaboración y creatividad, otras voces se hacen presentes a partir de un lugar de enseńanza de molde tradicional, en el cual se evalúa al alumno solo según criterios cuantitativos y por ello, el tema de la nota numérica es fundamental. El enlace "relatórios" también corrobora con esta arena de tensiones, puesto que se exige del alumno un desempeño satisfactorio que debe ser medido y cuantificado por el número de acceso a la plataforma. Los alumnos siguen siendo fiscalizados por el criterio cuantitativo de evaluación, algo de cierto modo "incompatible" con lo que se propone a la modalidad de enseñanza on line alineada al aprendizaje colaborativo e interactivo.

Esto viene a confirmar la noción de que nuestros discursos son contradictorios, que la construcción de sentidos se da siempre en un espacio de conflictos (Foucault, 2009), y el propio dialogismo de Bakhtin (2003) que postula que las palabras son siempre las palabras del Otro. No es por valernos de un soporte de lenguaje computacional (plataforma Moodle) que necesariamente trabajaremos de forma revolucionaria en la educación. Podemos también perpetuar discursos hegemónicos de la enseñanza tradicional aun hasta dentro de los ambientes virtuales (AVA). Basta que dispongamos la disciplina en la plataforma de forma dura y tradicional, que es lo que generalmente viene ocurriendo en el curso analizado.

Tomando por base la Teoría de los Discursos Sociales vista en Pinto (2002), el lenguaje y los sentidos propuestos por él son productos culturales ligados 


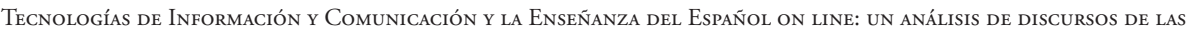
disciplinas Virtuales del curso de Letras Español a distancia de la UAB-UESPI

a su "instancia" de acontecimiento, o sea, a sus condiciones de producción. (Pechêux, 2008). Es por ello que nuestro análisis semiótico es indicial, pues analizamos en las imágenes las marcas en sus enunciados, de modo que sirvan de explicación a los fenómenos sociales que están explícitamente marcados por lo ideológico.

Cuando vemos en la figura 2 la imagen del aula con una pizarra según los moldes tradicionales, podemos decir que esta tiene su propósito, pues recordando a Joly (2005), en una perspectiva sociodiscursiva, toda imagen trae consigo elementos del contexto histórico-cultural. En consecuencia, no puede ser tratada como un texto puro y exento de intencionalidad. El uso de esta imagen como estrategia de enunciación de la disciplina revela un embate de conflictos entre el nuevo orden de discursos sobre educación y los discursos de la enseñanza tradicional, porque de hecho, si vamos a pensar sobre quién dispuso dicha disciplina en la plataforma, podemos decir que los sujetos no son únicos ni fuente última de sentidos para los fenómenos sociales. Por esto conviene adoptar la perspectiva de los varios sujetos de discursos. Por más que se quiera innovar dibujando y disponiendo una disciplina en ambiente virtual, aún hablamos de un lugar tradicional en educación que posee raíces históricas. Lo que decimos sigue siendo lo del otro, no hay discursos "nuevos" apartados de los "viejos".

Sobre esto, al analizar los discursos del webperiodismo, Dalmonte (2009) señala que la coexistencia de estos dos elementos (lo viejo y lo nuevo) también tiene que ver con el proceso de creación de identidades entre la instancia enunciadora y la destinataria en virtud del vínculo con lo "tradicional”, algo válido cuando se trata de lenguaje. 
Al seguir con el análisis, la construcción de la imagen de sí de esa disciplina pasa por un enunciador pedagógico.

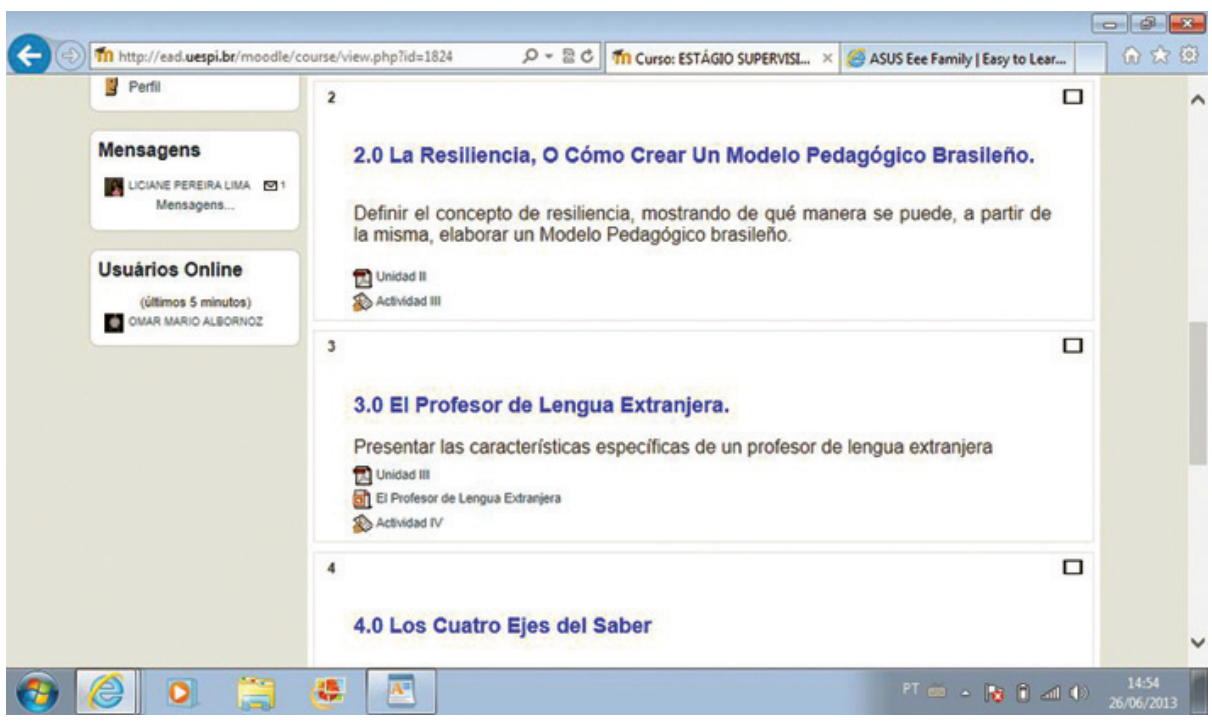

Figura 4 - Pásina de la disciplina Pasantía Supervidasa IV

Por ejemplo, podemos identificar ese enunciador pedagógico en los enunciados de las unidades 2 y 3 de la disciplina Pasantía Surpevisada IV (fig.4). Observando estos enunciados, vemos cómo la disciplina busca instruir al alumno sobre lo que tendrán que leer y hacer en las actividades propuestas. Se trata de una estrategia discursiva a través de contenidos puestos en $p d f$, word o powerpoint. Esta marca nos dice que no es por el hecho de hacer un curso a distancia que no tendremos contenidos y objetivos sistematizados para aprender y cumplir. El proceso de enseñanza, pues, se acerca al modus 


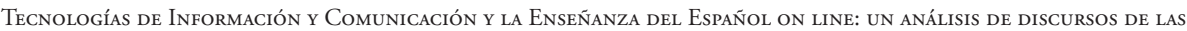
disciplinas Virtuales del curso de Letras Español a distancia de la UAB-UESPI

operandi de los cursos presenciales. Sin embargo, proponemos una cuestión: ¿no estaremos sólo extendiendo lo tradicional de la modalidad presencial a la enseñanza a distancia? ¿Introducir en estas disciplinas materiales salvados en $p d f$ o powerpoint sin ningún enlace interactivo nos conduce a una forma de enseñar lengua y literatura espańola más dinámica y creativa y por lo tanto interactiva? Estamos ante una nueva arena de tensiones en el universo de las plataformas que son generadoras de conflictos entre alumnos, profesores de lenguas extranjeras y la universidad misma y, que son silenciados bajo la condición de que la disciplina se enmarque en un ambiente virtual, y por lo tanto, "dinámico", "creativo" e "interactivo". Este foco de tensión es previsible porque estamos ante una recontextualización de la enseñanza superior en Brasil y en el mundo a través de la modalidad on-line, pues vivimos una práctica social de enseñanza y aprendizaje hegemónica alineada a la modalidad tradicional y presencial con todos sus géneros de discursos inherente. Podríamos decir que, por una cuestión de poder o reconocimiento institucionalizado a lo largo de nuestra historia, esta modalidad se extiende asimismo al ambiente virtual.

Sabemos que los textos de las disciplinas virtuales de lengua española tienen sus modos de referirse a su público, de interpelarlo y de establecer un diálogo con él, y de eso dependerá su aceptación o rechazo por parte del alumno que está cursando a distancia, y que las marcas enunciativas son el resultado de las convenciones de codificación exigidas por el contexto sociocultural en que se da el evento comunicacional específico. Al analizar estas disciplinas vemos alguna regularidad respecto a estas marcas. 


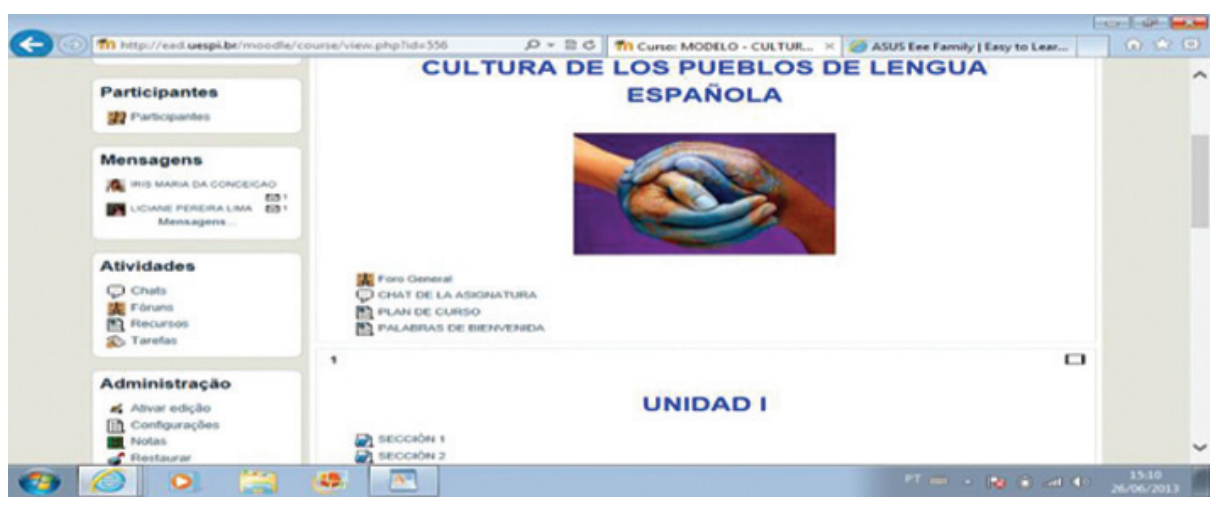

Figura 5 - Pásina de la disciplina Cultura de los Pueblos

Al hablar sobre la construcción de la imagen del tú, los modos de mostrar, interactuar y seducir son respectivamente: el uso referencial del lenguaje y de otras semióticas por las cuales se crean los universos de discursos en juego en el proceso comunicacional; la construcción de las identidades y relaciones sociales asumidas por los participantes (en lo concreto, los alumnos virtuales) en dicho proceso; la distribución de los afectos negativos o positivos asociados al universo de discurso respecto a la enseñanza on line, con el único fin de mantener la lectura de la disciplina y el alumno motivado. Para la mantención de esta lectura, se construye una imagen positiva de ese lector virtual a través de varias estrategias enunciativas a fin de seducirlo.

Así, podemos decir que la fotografía usada por la disciplina Cultura de los Pueblos (fig.5) de un globo terrestre entre manos que se entrelazan construye una imagen positiva de alumno y universidad, indicando que establecen su enseñanza y aprendizaje del conocimiento de modo colaborativo. Con esta imagen se seduce al lector y se lo invita al trabajo colectivo. Asimismo, si 


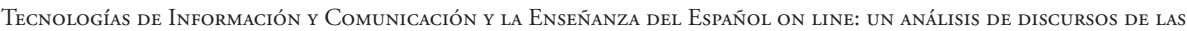
disciplinas virtuales del curso de Letras Español a distancia de la UAB-UESPI

observamos la página de esa disciplina (fig.5) y la de Literatura Espańola I (fig.6), vemos que nos enseñan otras estrategias enunciativas que de cierto modo llevan al alumno hacia el curso virtual como lector discursivo. Y una de esas estrategias de enunciación para la seducción ocurre por el uso de las herramientas "fórum" y "chat".

Como podemos ver en estas dos disciplinas, el ambiente de aprendizaje conlleva espacialmente varias interfaces con los enlaces "fórum" y "chat". Estos están presentes en ATIVIDADES al lado izquierdo de la página en la posición vertical y al centro, en la apertura de las disciplinas en "Foro general" (fig. 5) debajo de la fotografía de las manos y "Foro de la unidad primera y segunda" ( fig. 6), en los cuales el alumno discute sobre las disciplinas y sus contenidos en red. Estas estrategias de enunciación para el lenguaje de cursos on line funcionan como herramientas de cooperación e interacción. El foro se considera una de estas herramientas asíncronas de comunicación usada para discutir los más variados asuntos. Asimismo, el chat es una de esas herramientas síncronas de comunicación que simula un salón de charlas donde las personas se encuentran para hablar de cualquier tema.

Esa estrategia proporciona al texto los discursos sociales de la interactividad y la construcción colaborativa del conocimiento. Se construye la imagem de un tú o de un lector activo, característico de esa modalidad de enseñanza, un alumno curioso que debate, crea y recrea su expresión conforme la polifonía y el dialogismo (Bakhtin, 2003), aun cuando se vean en las plataformas de cursos on line comportamientos discentes pasivos e individualistas. 


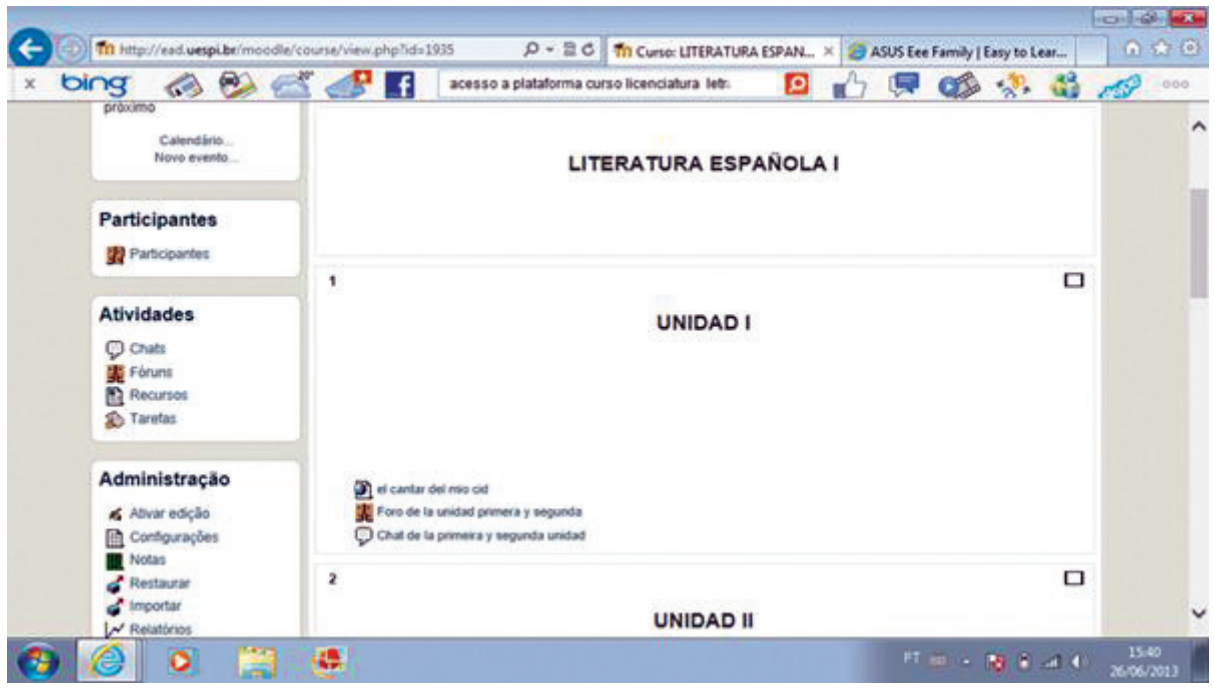

Figura 6 - Página de la disciplina Literatura Española |

Otra estrategia de enunciación que construye la imagen de un tú discursivo se revela en la interface PARTICIPANTES, ubicada al lado superior izquierdo de todas las disciplinas analizadas, tal como se aprecia en las figuras 5 y 6 . Al pinchar en este enlace, el alumno de Letras Español visualiza a todos sus compañeros de curso con su fotografía, perfil y e-mail. Con este enlace, se producen sentidos relacionados a un lector que antes que nada es una persona que tiene familia con deseos, creencias y valores. En la sección "perfil”, cada sujeto involucrado en el curso puede trazar su descripción personal. Y esta red de informaciones personales ayuda a la construcción de identidades colectivas y fortalecimiento de los lazos de amistades entre los participantes, donde cada uno busca reconocerse en 


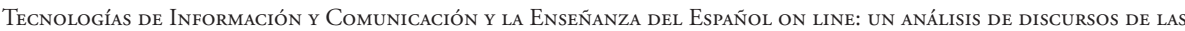
disciplinas virtuales del curso de Letras Español a distancia de la UAB-UESPI

LuCiana Maria Libório EULÁlio

el perfil del otro, identificándose con los compañeros de curso. El enlace "mensagens" aparece diseminado en el texto de las disciplinas como un enunciador tecnológico que construye una imagen positiva de ese lector (tú) como un alumno "en sintonía" con las nuevas formas de comunicarse en la era de las nuevas tecnologías.

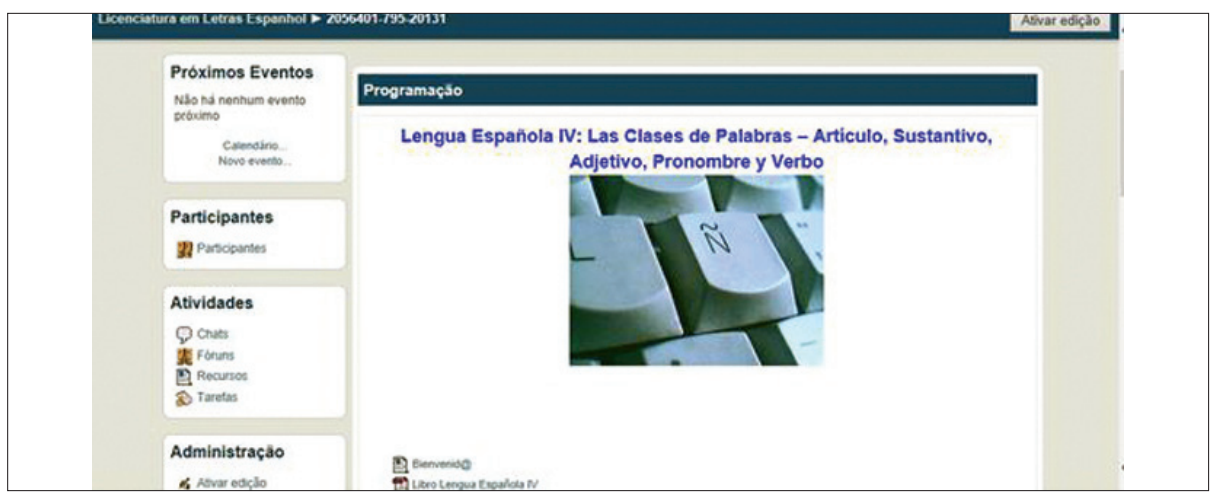

Figura7 - Página de la disciplina Lengua Española IV

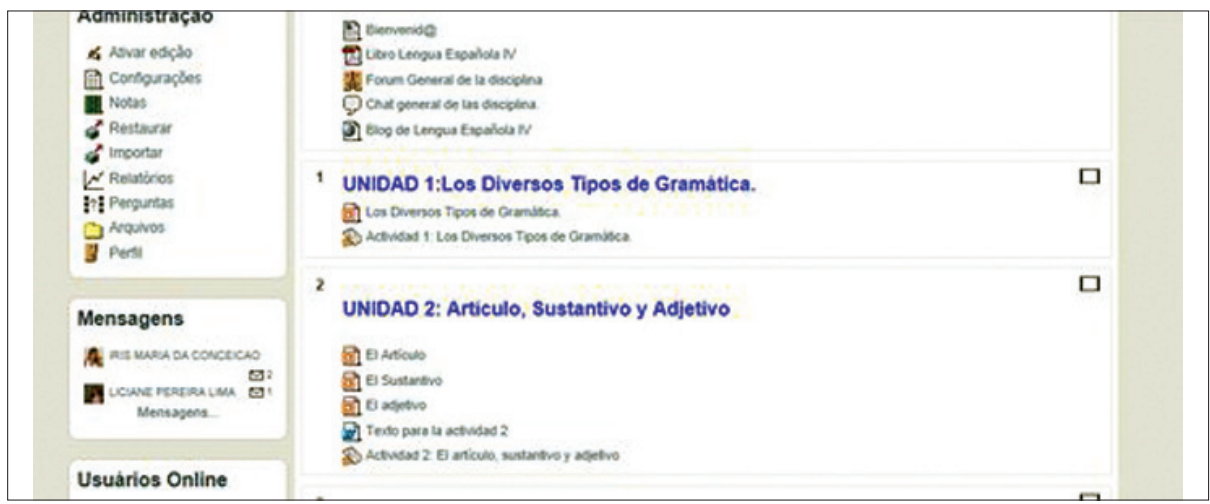

Figura 8 - Página de la disciplina Lengua Española IV 
En cuanto a las estrategias enunciativas de la disciplina Lengua Espańola IV (fig. 7 y 8), podemos afirmar que estas no divergen significativamente de las demás, pues para la construcción de la imagen de sí de la universidad se hacen presentes enunciadores institucionales como: el mismo banner, los enlaces "notas", "tarefas", "relatórios". En relación al enunciador pedagógico, advertimos sólo la presencia de materiales didácticos puestos en word, powerpoint y $p d f$ sin ninguna otra estrategia más interactiva. Asimismo, vimos en la parte central y superior de la disciplina este enunciador en el enlace "planos de curso", a través del cual, como en los moldes tradicionales, el profesor orienta al alumno sobre los contenidos que deberán ser estudiados en lengua española, las metodologías de trabajo realizado y las formas de evaluación en una perspectiva de instrucción. Se construye, pues, una imagen de sí de universidad muy cercana a los moldes tradicionales de enseñanza.

Es una tendencia actual de la Sociedad Colaborativa del Conocimiento del siglo XXI la escritura de textos realizada por varios autores y coautores. En la Sociedad de las Redes Interactivas se cree, a su vez, que sólo se produce conocimiento de forma colectiva. En relación a ello, la disciplina proporcionó una estrategia de enunciación no vista en las otras: el enlace "Blog de Lengua Española IV” (fig. 8), algo que entra en la construcción de la imagen de sí de modo positivo, produciendo sentidos para una universidad que acompaña la evolución de las tecnologías de digitalización de las informaciones y del conocimiento, así como los discursos de dicha sociedad colaborativa a través de este blog sobre lengua española. 


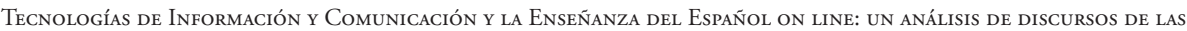
disciplinas Virtuales del curso de Letras Español a distancia de la UAB-UESPI

Configurando otra arena de tensión, vemos el uso de la imagen de un teclado de computadora donde se exponen las letras del alfabeto español en cada tecla para abrir la página de la disciplina de Lengua Espańola IV. La elección de esta imagen y no de otra revela una estrategia de enunciación que produce sentidos para una visión de lengua ligada a la norma, a la forma, descontextualizada y no comunicativa ni interactiva. Una vez más nos vemos un campo de batalla producido por el conflicto entre discursos tradicionales hegemónicos y nuevos discursos en el campo educativo.

\section{CONSIDERACIONES FINALES}

Como consideraciones finales y retomando la hipótesis propuesta, podemos considerar que esta se confirma ya que las representaciones didáctico-pedagógicas identificadas en las disciplinas relacionadas a la enseñanza del español, literatura, cultura y lengua española sugieren diferentes construcciones de sentido por la relación de conflictos entre sus enunciadores al interior de la formación discursiva de la Educación on line en virtud de las siguientes evidencias:

- las construcciones de sentido de los discursos presentes en el corpus analizado se dieron siempre en una relación de conflicto entre lo tradicional y lo nuevo, pues tenemos una tendencia a no incorporar rápidamente lo diferente, lo nuevo;

- nuestros discursos son contradictorios, de ahí que nos hayamos percibido/notado en las disciplinas del curso de Letras Español a distancia, 
discursos de la educación on line mezclados con los discursos hegemónicos de los paradigmas tradicionales de la educación;

- en la educación on line hay diferentes modos de incorporación de las TICs y eso genera múltiples implicaciones discursivas. La prueba de esto se encontró en algunos diferentes modos de concebir las herramientas de la plataforma Moodle utilizadas en las disciplinas, aunque hemos percibido/observado que todas mantuvieron casi el mismo formato;

- en el curso de Letras Español on line de UESPI todavía se reproduce el paradigma tradicional de enseńanza, en el que el profesor es el encargado de "transmitir" conocimientos e informaciones através del ejemplo de actividades propuestas para las cuatro disciplinas puestas em $p d f$, word, o webtextos que, por lo demás, muestran la herencia del discurso hegemónico sobre educación que sigue tratando al alumno como un recipiente de informaciones;

- la actualidad es un lugar de incertidumbres; por eso los discursos identificados en las cuatro disciplinas podrán ser borrados y sustituidos por otros discursos, ya que la realidad es cambiable, y la UESPI está en una fase intermedia de incorporación de estos nuevos discursos de interactividad y colaboración para el conocimiento, pues aun construyendo nuevos sentidos para enseñar la lengua y la cultura espańola en su curso de Letras Español a Distancia, sigue hablando de un lugar de discursos hegemónicos de la pedagogía tradicional que posee raíces históricas y profundas. 


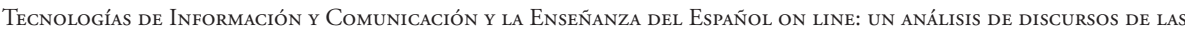
disciplinas VirTuales del curso de Letras Español a distancia de la UAB-UESPI

Finalmente, como dice Pêcheux (2008), los discursos son acontecimientos, los enunciados analizados del corpus por el momento son únicos, pero estarán abiertos a la repetición, reactivación, transformación, eliminación porque no está articulados sólo a las situaciones o contextos que los provocan y a las consecuencias por ellos ocasionados, sino también a los enunciados que los preceden y a que los siguen.

\section{REFERENCIAS BBBLIOGRÁFICAS}

Adorno, T.W. Educação e Emancipação. Tradução Wolfgang Leo Maar. Rio de Janeiro: Paz e Terra, 1995.

Bakhtin. Mikhail. "Os gêneros dos discursos”. In: Estética da criação verbal. Tradução de Paulo Bezerra. 4a ed. São Paulo: Martins Fontes, 2003.

Castells, Manuel. A era da informação: economia, sociedade e cultura. São Paulo: Paz e Terra, 1999, vol. 1.

Dalmonte, Edson Fernando. Pensar o discurso no webjornalismo. Salvador: EDUFBA, 2009.

Demo, Pedro. A nova LDB. Ranços e Avanços. Campinas, SP: Papirus, 1997. (Coleção Megistério: Formação e Trabalho Pedagógico).

Foucault, Michel. A Ordem do Discurso - aula inaugural no College de France, pronunciadaem2 de dezembro de 1970.19ª ed. São Paulo: Loyola, 2009. . Microfísica do poder. São Paulo: Paz e Terra, 2005.

Freire, Paulo. Pedagogia da autonomia: saberes necessários à prática educativa. São Paulo: Paz e Terra, 1996.

Joly, M. Introdução à análise de imagens. 9. ed. Campinas, SP: Papirus, 2005.

Kenski, Moreira Vani. Educação e tecnologias: o novo ritmo da informação. Campinas-SP: Papirus, 2007. 
Lévy, Pierre. "Educação e Cybercultura”. In: Lévy, Pierre, Cybercultura. Paris: Odle Jacob, 1993.

Pêcheux, Michel. O discurso. Estrutura ou acontecimento. Campinas: Pontes, 2008.

Pinto, Milton José. Comunicação e Discurso. 2ª ed. São Paulo: Hacker Editoras, 2002.

Pucci, Bruno. "Da ambivalência da Educação a Distância: reflexóes". In: Silva, Marco; Pesce Lucila; Zuin, Antônio (Orgs). Educação on line. Cenário, formação e questóes didático-metodológicas. Rio de Janeiro: Wak Ed, 2010.

Preti, Oreste (Org.). Educação a Distância: sobre discursos e práticas. Brasília: Líber Livro Editora, 2005.

Ruiz, Osvaldo Lopes. "Manuel de Castells e a 'era da informação". In: Com Ciência Eletrônica de Jornalismo Científico, n.30, 2002. Disponível em: http://www. comciencia.br/reportagens/internet/net16.htm

Snyder, Ilana. "Ame-os ou deixe-os: navegando no panorama de letramentos em tempos digitais". In: Araújo, Júlio César; Dieb, Messias (Org.). Letramentos na web: gêneros, interação e ensino. Fortaleza: UFC, 2009.

Verón, Eliseo. Fragmentos de un tejido. Barcelona: Gedisa, 2004. 